\title{
Validation Study of the Revised Spirituality and Spiritual Care Rating Scale (SSCRS): A Cross-Sectional Survey in Poland
}

\author{
Mariusz Panczyk 1, ${ }^{*}$, Lucyna Iwanow ${ }^{1}$, Beata Dobrowolska ${ }^{2}$, Ewa Borowiak ${ }^{3}$, Danuta Dyk ${ }^{4}$, Elżbieta Grochans ${ }^{5}$, \\ Dorota Kozieł 6, Maria Kózka 7, Halina Kulik ${ }^{8}$, Jolanta Lewko 9, Wilfred Mcsherry ${ }^{10}$, Joanna Gotlib 1, Mariusz \\ Jaworski $^{1}$
}

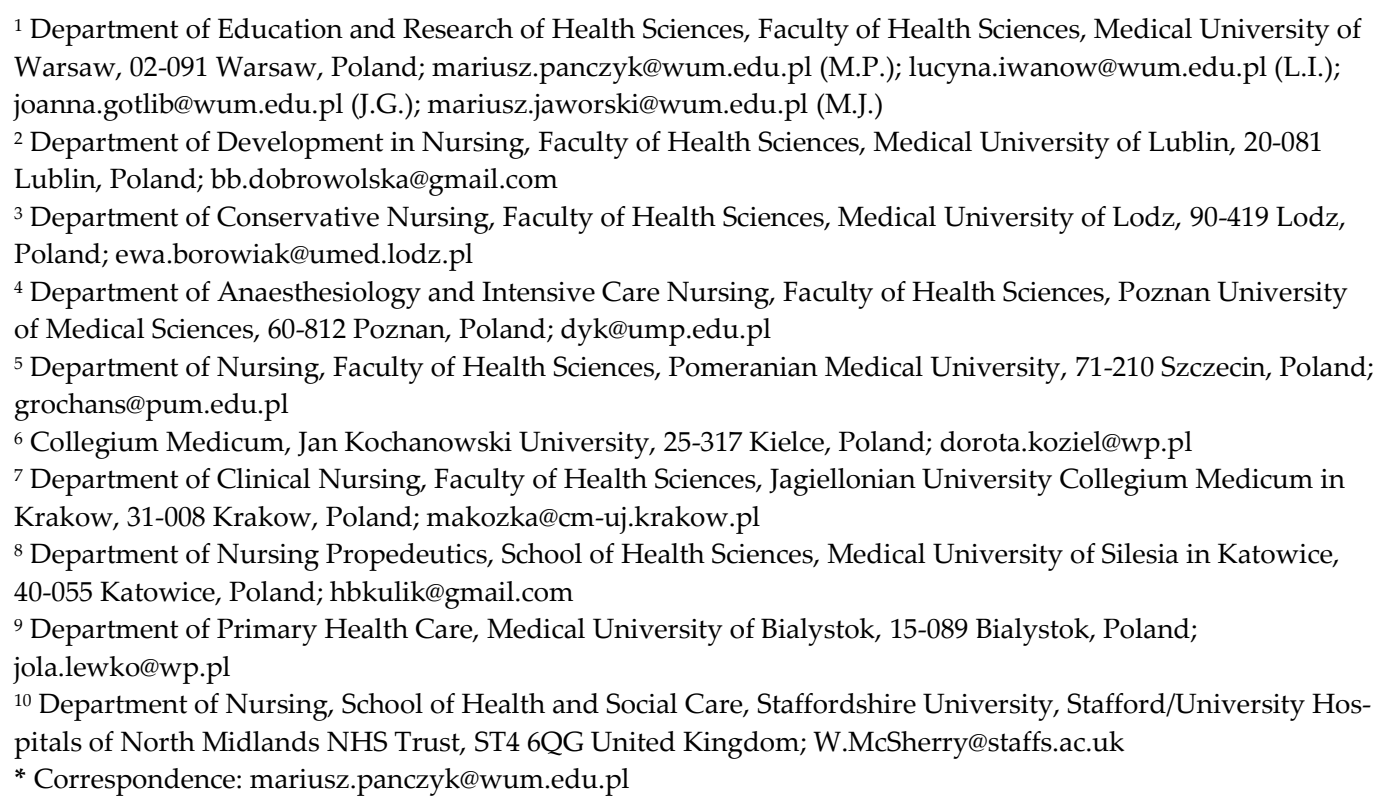

Abstract: The purpose of this study was to analyse selected psychometric properties of the Polish version of the Spirituality and Spiritual Care Rating Scale (SSCRS), among them the applicability of the dimensions of spiritual care in nursing, i.e. spirituality, spiritual care, religiosity and personalized care, to Polish conditions. Poland-wide multicentre study with a cross-sectional validation design. The study was conducted between March and June 2019. Seven Polish Nursing Faculties accepted the invitation to participate in the study. Representative sample of 853 nurses enrolled in MSc (postgraduate) programs in nursing. After translation and cultural adaption of the SSCRS, the instrument underwent a full psychometric evaluation with theoretical relevance using (exploratory, confirmatory factor analysis), internal consistency (Cronbach's alpha), reliability (test-retest analysis), construct validity (correlation analysis), criterion-related validity (convergent and discriminant validity) analysis. The exploratory and confirmatory factor analysis demonstrated that Polish version of the SSCRS was a three-factor model with "Activity-centred spiritual care" (9 items), "Emotional support-centred spiritual care" (5 items) and "Religiosity" ( 3 items) domains. The Cronbach's alpha coefficient for the whole scale was 0.902 , and the alpha values for the individual domains were $0.898,0.873$ and 0.563 , respectively. The three domains mentioned above seemed to provide the entire picture of spiritual care perceived subjectively by Polish MSc in nursing students. This study demonstrated a substantial degree of similarity in the selected psychometric characteristics of the Polish version of SSCRS and the original scale.

Keywords: spirituality; holistic nursing; nursing care; postgraduate nursing education

\section{Introduction}


Spiritual care (SC) is increasingly recognized by both international and national nurse organizations as an important component of holistic care [1-4]. The some organizations have been developing guidelines with regards to the education of nursing personnel in SC and emphasize the importance of spirituality in complex patient management $[2,4]$. SC was also shown to significantly improve the patients' compliance and well-being [57]. The growing role of SC in nursing practice was reflected in various initiatives, such as the National Coalition for Hospice and Palliative Care [3], and international projects, e.g. 'Enhancing Nurses' and Midwives' Competence in Providing Spiritual Care through Innovative Education and Compassionate Care' [8].

According to the NANDA International 2018-2020 guidelines [9], identification of patients' spiritual needs should be a component of nursing diagnosis. One of the recommendations is to develop and to implement courses on spirituality and SC in nursing schools [8]. Unfortunately, nursing professionals are not prepared well enough to provide SC [1]. Similar opinions have also been shared by the Spiritual Care Association [10,11]. Moreover, some authors claimed that SC offered by nurses is typically intuitive, instead of being based on relevant knowledge and skills [12].

SC is an important element considered by various accreditation organizations, and hence, adequate preparation of nursing candidates for providing this care should be an essential component of university curricula [13]. Education in this matter should centre around the primary principles of SC, such as listening, spending time with patients, respecting their privacy and dignity, maintaining religious practices, and delivering care with kindness and concern [14-16].

The question of SC has been discussed extensively. Despite that consensus definition by Puchalski et al [17]. is widespread use, to it is still under debate. This debate is associated with the subjective nature of spirituality, which to a large degree depends on an individual's own worldview and interpretation of the concept [18]. The abovementioned controversies may hinder adequate involvement of nurses in satisfying the spiritual needs of their patients [19]. Frequently observed insufficient level of SC might also pose a challenge in the modern nurses' education $[11,20]$. This warrants the use of dedicated instruments, not only to measure nurses' skills in SC but also to analyse the spiritual needs of their patients.

The psychometric instruments that can be used to examine the phenomenon of spirituality, attitudes and needs related to SC include those dedicated to students and medical personnel (also nurses), as well as patient scales [21-26]. The latter group includes such instruments as the Spiritual Needs Assessment for Patients (SNAP) [26], Spiritual Needs Questionnaire (SpNQ, version 1.2.) [21], and Quality of Spiritual Care (QSC) [22]. All these provide information about the spiritual needs of patients, as well as about the satisfaction of patients and their relatives with the SC received. Given this scope of information, these instruments are invaluable in supporting the work of nurses.

Questionnaires dedicated to medical personnel include such instruments as the Spirituality Assessment Scale (SAS) [23], Spirituality Measurement Scale (SMS) [24], and Spirituality and Spiritual Care Rating Scale (SSCRS) [25]. SAS consists of four subscales: purpose and meaning in life, interconnectedness (connectedness to others and environment), innerness (inner peace and inner strength in times of difficulties), and transcendence [23]. In turn, SMS measures five dimensions: transcendence, self-engagement, self-efficacy, self-awareness, and service towards others. This instrument examines the spirituality of an individual based on the assumption that every person is a spiritual being; it is, however, the awareness of one's spirituality that differentiates between two individuals [24]. Another important scale to determine the spirituality and nurses' attitudes towards spiritual care is the SSCRS. The authors of this scale identified four domains: spirituality, spiritual care, religiosity and personalised care [25].

\subsection{Conceptual Framework}


The lack of adequate competencies in terms of SC results in nurses' feeling inadequately preparedness to support these needs [27]. This warrants activities to enhance the effectiveness of SC in practice. According to Ross [28] such activities should also be included in the continuing education programs for nurses. Through adequate training, nurses could gain competencies necessary to provide SC more effectively. As a result, they would not only better understand the underlying ideas of SC, but could also utilize this knowledge in clinical practice [29]. To prepare adequate, effective training programs strengthening nurses' competencies, one needs the scales that comprehensively measure and characterize the issues related to SC. One such scales seems to be the SSCRS which distinguishes between the religiosity and spirituality, and measures nurses' attitudes towards SC [25]. Unlike the Spirituality Assessment Scale [23] and Spirituality Measurement Scale [24], both focusing primarily on the awareness of one's spirituality, SSCRS is suitable for a comprehensive analysis of the personal resources, and hence, can help strengthen those resources through a well-designed training programme.

\subsection{Aim}

The aim of the study was to analyse selected psychometric properties of the Polish version of the SSCRS (SSCRS_P), establishing the applicability of the dimensions of spiritual care proposed by McSherry, Draper and Kendrick [25] i.e. spirituality, spiritual care, religiosity and personalised care, to Polish conditions.

\section{Methods}

\subsection{Design}

This Poland-wide multicentre study with a cross-sectional validation design included a representative sample of 853 nurses enrolled in MSc programs in nursing. The study was conducted between March and June 2019.

\subsection{Sample and Setting}

A total of 16 academic faculties offering MSc programs in nursing were invited to participate in the study. The number of nurses enrolled on the MSc programs (level VII according to the European Qualifications Framework) at those faculties is approximately 6,000, which corresponds to $90 \%$ of all Polish post-graduate students [30]. The formal invitation emails were sent to Heads of Nursing Faculties. Seven Nursing Faculties, which educates a total of 2,000 nurses pursuing the MSc title, accepted this invitation. Complete data were obtained from 853 respondents (response rate $42.6 \%$ ). Considering this sample size and the overall number of nurses enrolled in the MSc programs in Poland $(\mathrm{N}=6,000)$, the error margin was 3.17\% (95\% confidence level and proportion 0.50$)$ [31].

\subsection{Ethical Considerations}

Before the study, verbal informed consent to participate was obtained from each recruited nurse. Information about the objectives of the study, the methods of data analysis and archiving was provided in a written form. Moreover, the respondents were assured that their personal data would be used solely for research purposes. Each participant could withdraw from the study at any stage. According to the Local Inspector for Personal Data Protection, considering the type of data collected within the framework of the study, no additional consent for personal information processing had to be sought from the participants. The protocol of the study was approved by the Bioethics Committee at the Medical University of Warsaw (AKBE/152/16).

\subsection{Instrument}

The Spirituality and Spiritual Care Rating Scale (SSCRS) was developed by McSherry, Draper and Kendrick [25] to measure spirituality and spiritual care in nursing. The SSCRS is a 17-item instrument with four factor-based subscales. Subscale I "Spirituality (existential elements)", consists of 5 statements about the broader concept of 
spirituality incorporating existential elements. Sample item: I believe spirituality is about finding meaning in the good and bad events of life. Subscale II "Spiritual Care" includes five statements referring to the main rudiments of spiritual care. Sample item: I believe nurses can provide spiritual care by arranging a visit by the hospital Chaplain or the patient's religious leader if requested. Subscale III "Religiosity" has three statements according to which spirituality is not only a concept associated with religion. Sample item: I believe spirituality does not apply to Atheists or Agnostics. Subscale IV "Personalised Care" consists of 3 statements about personalised care, specific to the individual. The link between the spirituality and one's beliefs, values, morals and relationships are vital in the context of personalised care. Sample item: I believe spirituality involves personal friendships, relationships.

The original SSCRS demonstrated a reasonable internal consistency rate, for a newly developed scale with a Cronbach's alpha coefficient of 0.64 [25].

\subsection{Translation and cultural adaption of the SSCRS}

Linguistic-cultural adaptation and validation of the Polish version of the SSCRS were carried out in line with the guidelines developed by Sousa and Rojjanasrirat (2011). The translation and validation procedure consisted of four phases. The original SSCRS, in the form published by McSherry, Draper and Kendrick [25], was translated into Polish by two independent interpreters. After reaching a consensus, the two translated versions of the SSCRS were combined into a single scale. Then, this version was translated back into English by two independent bilingual interpreters (a healthcare professional bilingual in English and Polish, and a native Polish with a university degree in English), both blinded to the original version of the SSCRS. The two back-translated scales were reviewed by McSherry, the author of the original SSCRS. Based on his feedback, a multidisciplinary team of experts carried out a transcultural equivalence analysis of the original SSCRS and SSCRS_P. The multidisciplinary team consisted of an expert in statistical validation methods, all members of the research team, and three interpreters involved in the translation during the first two phases. The members of the team reached a consensus and developed the version of the SSCRS_P to be used during the pre-testing phase. The Polish version of the SSCRS was pretested in a randomly selected cohort of 10 nurses enrolled in the MSc programs. The pre-test confirmed that all questions were understandable, but some minor lexical changes were implemented. Eventually, the final Polish version of the SSCRS was developed and used during further validation stages to determine its psychometric properties (see Appendix 1).

\subsection{Data collection}

The data were collected with a self-report survey. The questionnaires were completed by a group of nurses enrolled in the MSc programs, gathered in a single classroom after regular academic classes. The trained questioners provided the respondents with verbal information about the objectives of the study and instructed them on how to complete the survey. Then, the questioners collected completed surveys and secured them until they were sent to the central unit coordinating the study. The questioners were not previously involved in the education of the respondents from whom they collected the surveys to eliminate any form or coercion, discomfort and pressure inherent to the teacher-researcher role. The data collected with the paper surveys were digitalized using ABBYY® FlexiCapture version 9.0 software. Then, the database was screened for atypical and erroneous records and cleaned with automatic instruments. Whenever possible, corrections were made based on the inspection of the paper surveys. Incomplete surveys were excluded from the validation process. The digitalized data were secured and archived for five years, in line with the standard operating procedures of the Medical University of Warsaw

\subsection{Data analysis}


A full psychometric evaluation of the SSCRS_P was carried out, to determine theoretical relevance (exploratory and confirmatory factor analysis), internal consistency (Cronbach's alpha), reliability (test-retest analysis), construct validity (correlation analysis), and criterion-related validity (convergent and discriminant validity) of the scale. The psychometric evaluation of the SSCRS_P was carried out in line with the guidelines published by Boateng, et al. [32].

Item analysis concerned the assessment of the results using descriptive statistics (mean (M), standard deviation (SD), skewness and kurtosis). The compliance of the SSCRS_P score with the normal distribution was also estimated (D'Agostino's K-squared test). Floor or ceiling effects were considered present if more than $15 \%$ of the participants reported either the highest or the lowest possible SSCRS_P scores [33].

The exploratory and confirmatory factor analysis were performed independently on a random half of the collected data. Exploratory factor analysis (EFA) with direct oblimin rotation was used to evaluate the theoretical relevance of the scale. The number of factors was determined based on Kaiser's criteria [34]. Items to be included in respective factors were identified on a priori grounds, i.e., as items that loaded at more than 0.40 on one factor and at least 0.10 lower on another factor [35]. The principal component analysis was used for the extraction method.

Confirmatory factor analysis (CFA) was carried out to estimate the goodness of fit of the obtained results to the imposed structure based on the original SSCRS study by McSherry, Draper and Kendrick [25] or derived from the new EFA results. The expected values of recommended indices were as follows: $\chi^{2}$ divided by the degrees of freedom $\left(\chi^{2} /\right.$ df ratio $) \leq 3.00$; the Root Mean Squared Error of Approximation (RMSEA); the Comparative Fit Index (CFI) and the Tucker Lewis index (TLI) $>0.90$ [36]. The maximum likelihood estimation technique was used.

Internal consistency of the SSCRS_P was estimated based on Cronbach's alpha, with the alpha greater than 0.700 considered as a satisfactory internal consistency rate [37].

Test-retest reliability: A subset of students $(\mathrm{N}=23)$ were asked to complete the SSCRS_P once again approximately two weeks after the first survey [38]. Absolute stability of the scale was measured based on intraclass correlation coefficients (ICC) and the mean difference between the two measurements for each item of the SSCRS_P (paired ttest).

Construct validity of the scale was tested based on the assumption that there would be a negative association between the professional activities and the SSCRS_P score (Student's t-test). Convergent validity: The SSCRS_P was compared with the global score, and inter-item correlations (Pearson's correlation coefficients) were determined. Discriminant validity: students with a history of spiritual care training, and those who attended a communication skills course were expected to have higher SSCRS scores (Student's t-test).

All statistical calculations were carried out with STATISTICA version 13.3 package (TIBCO Software Inc., Palo Alto, California, United States) and Mplus version 7.0 software (Los Angeles, California, United States) [39]. The statistical null hypothesis was rejected if the two-tailed $p<0.05$.

\section{Results}

\subsection{Participant Characteristics}

The most of the participants were women $(\mathrm{N}=801,93.3 \%)$, and persons who living in cities with $>500$ thousand residents $(\mathrm{N}=267,31.3 \%)$. About $2 / 3$ of the participants $(\mathrm{N}=$ $553,64.8 \%)$ were under the age of 30 . The most of the participants $(\mathrm{N}=720,84.4 \%)$ had more than 3 years of clinical experience in nursing. Most of the respondents declared no communication skills training $(\mathrm{N}=684,80.2 \%)$. On the other hand, nearly $3 / 4$ of the respondents $(\mathrm{N}=608,71.3 \%)$ took part in spiritual care training. Detailed sample characteristics are presented in Table 1.

Table 1. Participant characteristics. 


\begin{tabular}{|c|c|c|c|c|c|c|}
\hline & \multicolumn{2}{|c|}{$\begin{array}{l}\text { 1st year } \\
(\mathrm{N}=350)\end{array}$} & \multicolumn{2}{|c|}{$\begin{array}{l}\text { 2nd year } \\
(\mathrm{N}=503)\end{array}$} & \multicolumn{2}{|c|}{$\begin{array}{c}\text { Total } \\
(\mathrm{N}=853)\end{array}$} \\
\hline & $\mathbf{N}$ & $\%$ & $\mathbf{N}$ & $\%$ & $\mathbf{N}$ & $\%$ \\
\hline \multicolumn{7}{|l|}{ Gender } \\
\hline Female & 329 & 94.0 & 472 & 93.8 & 801 & 93.9 \\
\hline Male & 21 & 6.0 & 31 & 6.2 & 52 & 6.1 \\
\hline \multicolumn{7}{|l|}{ Place of residence } \\
\hline Countryside & 79 & 22.6 & 89 & 17.7 & 168 & 19.7 \\
\hline $\begin{array}{l}\text { Village (population up to } 50 \\
\text { thousand) }\end{array}$ & 52 & 14.9 & 82 & 16.3 & 134 & 15.7 \\
\hline Small town (51-200 thousand) & 45 & 12.9 & 75 & 14.9 & 120 & 14.1 \\
\hline Large town (201-500 thousand) & 59 & 16.9 & 102 & 20.3 & 161 & 18.9 \\
\hline City $>500$ thousand & 115 & 32.9 & 152 & 30.2 & 267 & 31.3 \\
\hline Missing data & 0 & 0.0 & 3 & 0.6 & 3 & 0.4 \\
\hline \multicolumn{7}{|l|}{ Age [years] } \\
\hline$\leqslant 30$ & 239 & 68.3 & 314 & 62.4 & 553 & 64.8 \\
\hline $31-40$ & 20 & 5.7 & 41 & 8.2 & 61 & 7.2 \\
\hline $41-50$ & 69 & 19.7 & 103 & 20.5 & 172 & 20.2 \\
\hline$>50$ & 20 & 5.7 & 32 & 6.4 & 52 & 6.1 \\
\hline Missing data & 2 & 0.6 & 13 & 2.6 & 15 & 1.8 \\
\hline \multicolumn{7}{|l|}{ Clinical experiance } \\
\hline$\geqslant 3$ years & 269 & 76.9 & 451 & 89.7 & 720 & 84.4 \\
\hline$<3$ years & 72 & 20.6 & 41 & 8.2 & 113 & 13.2 \\
\hline missing data & 9 & 2.5 & 11 & 2.1 & 20 & 2.4 \\
\hline \multicolumn{7}{|l|}{ Spiritual care training * } \\
\hline Yes & 249 & 71.1 & 359 & 71.4 & 608 & 71.3 \\
\hline No & 98 & 28.0 & 133 & 26.4 & 231 & 27.1 \\
\hline Missing data & 3 & 0.9 & 11 & 2.2 & 14 & 1.6 \\
\hline \multicolumn{7}{|l|}{ Communication skills training ** } \\
\hline Yes & 52 & 14.9 & 88 & 17.5 & 140 & 16.4 \\
\hline No & 292 & 83.4 & 392 & 77.9 & 684 & 80.2 \\
\hline Missing data & 6 & 1.7 & 23 & 4.6 & 29 & 3.4 \\
\hline
\end{tabular}

* Declared participation in training covering the issues of spirituality, spiritual care and spiritual needs of patients.

** Declared participation in a communication skills course.

\subsection{Item analysis}

Mean overall SSCRS_P score for the study group was 60.66 (SD =10.94), with individual results ranging between 17.0 and 85.0. The results were skewed left (skewness = 0.92) and lacked normal distribution. None of the items had SD equal to zero. The scores for most items were not distributed normally (D'Agostino's K-squared test) (Table 2). The lowest and the highest possible overall scores of SSCRS_P were obtained in $2(0.23 \%)$ and $3(0.35 \%)$ respondents, respectively (no floor and ceiling effect).

Table 2. Descriptive statistics for SSCRS_P scores.

\begin{tabular}{lcccccc}
\hline Item & Mean & SD & Skew & Kurtosis & K $^{2}$ & $p$-value \\
\hline SSCRS_1 & 4.13 & 1.31 & -1.41 & 0.71 & 179.220 & $<0.001$ \\
SSCRS_2 & 4.09 & 1.29 & -1.42 & 0.79 & 181.486 & $<0.001$ \\
SSCRS_3 & 3.73 & 1.17 & -0.67 & -0.31 & 58.842 & $<0.001$ \\
SSCRS_4* & 4.07 & 1.27 & -1.27 & 0.47 & 150.682 & $<0.001$ \\
SSCRS_5 & 3.55 & 1.39 & -0.60 & -0.93 & 169.444 & $<0.001$ \\
SSCRS_6 & 3.89 & 1.19 & -1.04 & 0.25 & 111.050 & $<0.001$
\end{tabular}




\begin{tabular}{lllllll} 
SSCRS_7 & 3.99 & 1.19 & -1.21 & 0.57 & 143.032 & $<0.001$ \\
SSCRS_8 & 3.58 & 1.24 & -0.57 & -0.59 & 66.663 & $<0.001$ \\
SSCRS_9 & 3.63 & 1.17 & -0.58 & -0.37 & 49.480 & $<0.001$ \\
SSCRS_10 & 3.58 & 1.21 & -0.56 & -0.49 & 54.608 & $<0.001$ \\
SSCRS_11 & 3.84 & 1.23 & -0.97 & -0.07 & 98.545 & $<0.001$ \\
SSCRS_12 & 3.74 & 1.24 & -0.79 & -0.31 & 76.611 & $<0.001$ \\
SSCRS_13* & 3.17 & 1.27 & 0.01 & -0.99 & 176.461 & $<0.001$ \\
SSCRS_14 & 4.11 & 1.13 & -1.35 & 1.07 & 177.943 & $<0.001$ \\
SSCRS_15 & 3.85 & 1.14 & -0.85 & -0.04 & 79.377 & $<0.001$ \\
SSCRS_16* & 3.66 & 1.25 & -0.62 & -0.50 & 62.888 & $<0.001$ \\
SSCRS_17 & 3.83 & 1.19 & -0.90 & 0.01 & 87.699 & $<0.001$ \\
\hline Total score & 60.66 & 10.94 & -0.92 & 1.28 & 115.147 & $<0.001$ \\
\hline
\end{tabular}

* reverse score items

** D'Agostino's K-squared test

SD - standard deviation

\subsection{Exploratory and Confirmatory Factor Analysis}

First, it was verified if the study dataset satisfied the conditions of the EFA. The determinant of a correlation matrix was near zero $(<0.001)$. Also, the sphericity condition was satisfied (Bartlett's test, $\chi^{2}=7293.059, \mathrm{df}=136, p<0.001$ ). The sampling adequacy measure, assessed using Kaiser-Meyer-Olkin Measure of Sampling index, was 0.916 $(\mathrm{KMO}>0.5)$.

EFA demonstrated that up to 17 items included in the SSCRS_P satisfied Kaiser's criteria for three factors, unlike in the original scale, which consisted of four domains. Cumulatively, $60 \%$ of the variance was accounted for by the three factors (Table 3 ).

Table 3. Principal component analysis.

\begin{tabular}{cccc}
\hline \multicolumn{4}{c}{ Initial Eigenvalues } \\
\hline Component & Total & \% of Variance & Cumulative \% \\
\hline 1 & 7.018 & 41.285 & 41.285 \\
2 & 1.897 & 11.158 & 52.443 \\
3 & 1.269 & 7.462 & 59.905 \\
\hline
\end{tabular}

Although the three-factor model was not consistent with the four-domain concept of the original SSCRS, it was easier for interpretation than the latter. Based on the content of the items retained in the three identified factors, the following three domains were identified: "Activity-centred spiritual care (AcSC)" (9 items), "Emotional support-centred spiritual care (EsSC)" (5 items) and "Religiosity" (3 items). The items with their loadings on each factor are shown in Table 4.

Table 4. Pattern matrix with loadings for each item on each of the three factors (Rotation method: oblimin; Extraction method: principal component analysis).

\begin{tabular}{|c|c|c|c|c|c|}
\hline & \multirow{2}{*}{ Item } & \multirow{2}{*}{ Statement } & \multicolumn{3}{|c|}{ Component } \\
\hline & & & 1 & 2 & 3 \\
\hline A & SSCRS_1 & $\begin{array}{l}\text {... nurses provide spiritual care by arranging a visit by the hospital } \\
\text { chaplain or the patient's own religious leader if requested }\end{array}$ & 0.807 & 0.298 & -0.219 \\
\hline B & SSCRS_2 & $\begin{array}{l}\text {... nurses provide spiritual care by showing kindness, concern and } \\
\text { cheerfulness when giving care }\end{array}$ & 0.856 & 0.345 & -0.223 \\
\hline C & SSCRS_3 & $\begin{array}{l}\text {... spirituality is concerned with a need to forgive and a need to be } \\
\text { forgiven }\end{array}$ & 0.717 & 0.400 & -0.020 \\
\hline
\end{tabular}




\begin{tabular}{|c|c|c|c|c|c|}
\hline $\mathrm{D}$ & SSCRS_4 & ... spirituality involves only going to church/place of worship & -0.491 & -0.144 & 0.618 \\
\hline E & SSCRS_5 & $\begin{array}{l}\ldots \text { spirituality is not concerned with a belief and faith in a God or } \\
\text { supreme being }\end{array}$ & 0.417 & 0.238 & -0.357 \\
\hline $\mathrm{F}$ & SSCRS_6 & $\begin{array}{l}\text {... spirituality is about finding meaning in the good and bad events of } \\
\text { life }\end{array}$ & 0.743 & 0.476 & -0.292 \\
\hline G & SSCRS_7 & $\begin{array}{l}\text {... nurses provide spiritual care by spending time with a patient, } \\
\text { giving support and reassurance, especially in time of need }\end{array}$ & 0.819 & 0.555 & -0.286 \\
\hline $\mathrm{H}$ & SSCRS_8 & $\begin{array}{l}\text {... nurses provide spiritual care by enabling a patient to find meaning } \\
\text { and purpose in their illness }\end{array}$ & 0.404 & 0.787 & -0.043 \\
\hline I & SSCRS_9 & ... spirituality is about having a sense of hope in life & 0.384 & 0.838 & -0.046 \\
\hline $\mathrm{J}$ & SSCRS_10 & $\begin{array}{l}\text {... spirituality is to do with the way one conducts one's life here and } \\
\text { now }\end{array}$ & 0.341 & 0.797 & -0.061 \\
\hline $\mathrm{K}$ & SSCRS_11 & $\begin{array}{l}\text {... nurses provide spiritual care by listening to and allowing patients } \\
\text { time to discuss and explore their fears, anxieties and troubles }\end{array}$ & 0.505 & 0.810 & -0.225 \\
\hline $\mathrm{L}$ & SSCRS_12 & $\begin{array}{l}\text {... spirituality is a unifying force which enables one to be at peace with } \\
\text { oneself and the world }\end{array}$ & 0.457 & 0.810 & -0.217 \\
\hline $\mathrm{M}$ & SSCRS_13 & $\begin{array}{l}\text {... spirituality does not include areas such as art, creativity and self- } \\
\text { expression }\end{array}$ & -0.032 & -0.080 & 0.774 \\
\hline $\mathrm{N}$ & SSCRS_14 & $\begin{array}{l}\text {... nurses provide spiritual care by having respect for privacy, dignity } \\
\text { and religious and cultural beliefs of a patient }\end{array}$ & 0.824 & 0.483 & -0.329 \\
\hline $\mathrm{O}$ & SSCRS_15 & ... spirituality involves personal friendships, relationships & 0.758 & 0.491 & -0.210 \\
\hline $\mathrm{P}$ & SSCRS_16 & ... spirituality does not apply to Atheists or Agnostics & -0.359 & -0.125 & 0.709 \\
\hline Q & SSCRS_17 & ... spirituality includes people's morals & 0.635 & 0.357 & -0.218 \\
\hline
\end{tabular}

Items in factor are grey

Using the CFA, the goodness of fit of the study data was verified against the 4-factor model (original version of the SSCRS) and the 3-factor model (new version of SSCRS_P). The ratio of chi-square statistic to the degrees of freedom $\left(\chi^{2} / \mathrm{df}\right)$ was found to be 17.50 for the original model structure $\left(\chi^{2}=1995.348, \mathrm{df}=114\right)$ and 7.50 for the new model structure $\left(\chi^{2}=869.479, \mathrm{df}=116\right)$. The RMSEA for the original model and the new model was 0.139 (90\% CI [0.134-0.144]) and 0.087 (90\% CI [0.082-0.093]), respectively, whereas the TLI equalled 0.689 and 0.878 , respectively, and the CFI value amounted to 0.739 and 0.896 , respectively. The TLI and CFI values approximating 0.90 imply that the new 3-factor model structure of the SSCRS_P had a better goodness fit than the original 4-factor model structure. Detailed results of the CFA are depicted on the path diagram (Fig. 1). 


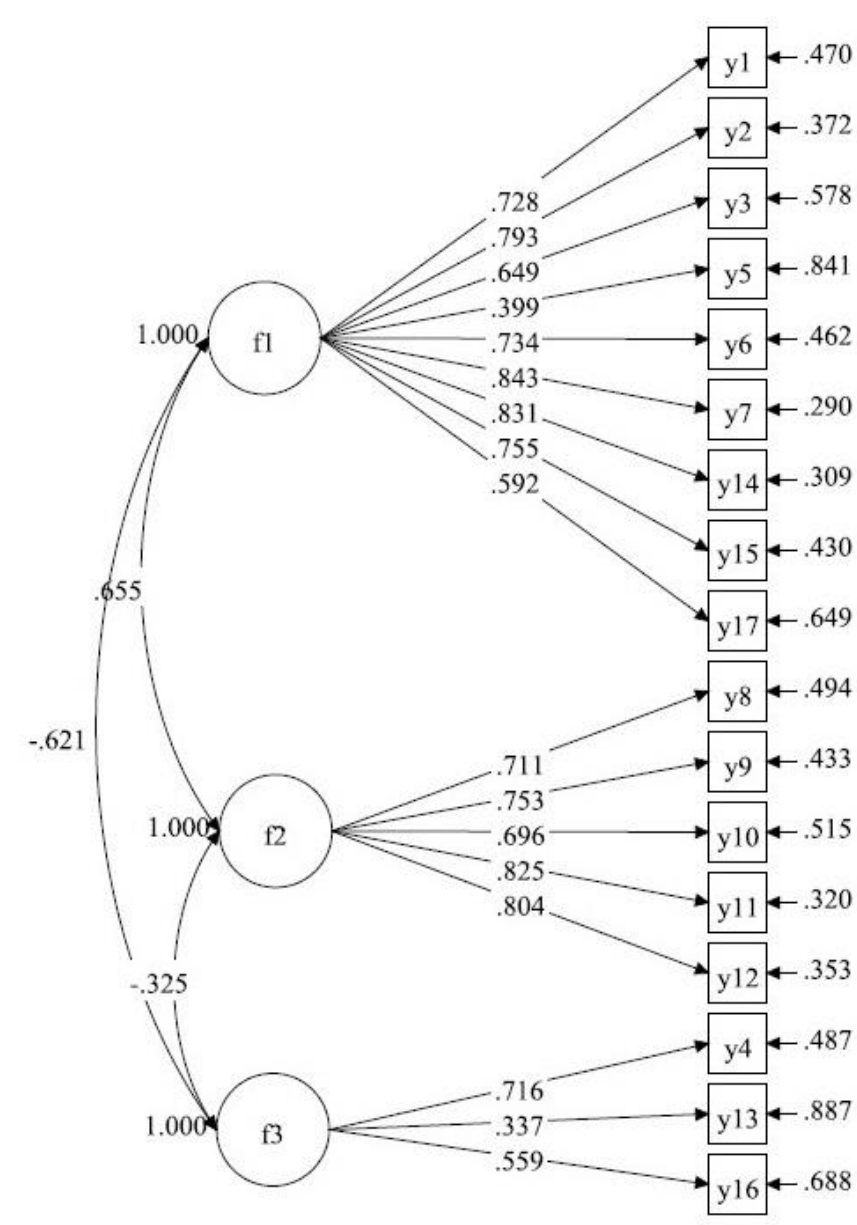

Figure 1. Detailed results of the CFA are depicted on the path diagram.

\subsection{Internal consistency}

Cronbach's alpha values for the three domains of the SSCRS_P were 0.898 ("AcSC"), 0.873 ("EsSC"), and 0.563 ("Religiosity"), whereas the alpha for the whole scale was 0.902. Correlation coefficients between individual items and the total scale score minus the individual items ranged between 0.14 and 0.77 (see Table S1: Appendix 2).

\subsection{Test-retest reliability}

Two-week test-retest reliability confirmed good stability of the SSCRS_P domains. The assumption on the equality of the means for the repeated measurements was confirmed, and the ICCs for the items were within a satisfactory range (Table 5).

Table 5. Test-retest reliability analysis.

\begin{tabular}{lccccc}
\hline Item & ICC & $\begin{array}{c}\text { Mean } \\
\text { difference } \\
\mathbf{( 9 5 \% ~ C I )}\end{array}$ & $p$-value & $\begin{array}{c}\text { Domain ICC } \\
\mathbf{( 9 5 \% ~ C I ) * *}\end{array}$ & $\begin{array}{c}\text { Mean } \\
\text { difference } \\
\mathbf{9 5 \%} \text { CI) }\end{array}$ \\
\hline SSCRS_1 & 0.520 & $-0.26(-0.82 ; 0.30)$ & 0.342 & 0.928 & -1.32 \\
SSCRS_2 & 0.580 & $-0.17(-0.67 ; 0.33)$ & 0.477 & $(0.876 ; 0.965)$ & $(-4.08 ; 1.44)$ \\
SSCRS_3 & 0.698 & $-0.01(-0.43 ; 0.43)$ & 0.999 & $\mathrm{P}=0.000$ & $\mathrm{P}=0.332^{*}$ \\
SSCRS_5 & 0.782 & $0.22(-0.19 ; 0.63)$ & 0.285 & &
\end{tabular}




\begin{tabular}{llcccc}
${ } }$ & 0.439 & $-0.13(-0.69 ; 0.43)$ & 0.632 & & \\
SSCRS_7 & 0.681 & $-0.35(-0.77 ; 0.08)$ & 0.103 & & \\
SSCRS_14 & 0.810 & $-0.04(-0.40 ; 0.31)$ & 0.803 & & \\
SSCRS_15 & 0.185 & $-0.18(-0.69 ; 0.32)$ & 0.463 & & \\
SSCRS_17 & 0.831 & $-0.34(-0.62 ;-0.06)$ & 0.017 & & -1.04 \\
\hline SSCRS_8 & 0.761 & $-0.22(-0.63 ; 0.19)$ & 0.285 & & $(-2.52 ; 0.43)$ \\
SSCRS_9 & 0.812 & $-0.04(-0.42 ; 0.34)$ & 0.814 & 0.783 & \\
SSCRS_10 & 0.326 & $-0.39(-0.86 ; 0.07)$ & 0.095 & $(0.621 ; 0.894)$ & \\
SSCRS_11 & 0.764 & $-0.26(-0.61 ; 0.09)$ & 0.137 & $\mathrm{P}=0.000$ & $\mathrm{P}=0.157^{*}$ \\
SSCRS_12 & 0.605 & $-0.13(0.46 ; 0.20)$ & 0.417 & & 0.17 \\
\hline SSCRS_4 & 0.149 & $0.13(-0.48 ; 0.74)$ & 0.665 & 0.746 & $(-0.84 ; 1.20)$ \\
SSCRS_13 & 0.621 & $-0.09(-0.45 ; 0.28)$ & 0.627 & $(0.542 ; 0.878)$ & $(17)$ \\
SSCRS_16 & 0.805 & $0.13(-0.25 ; 0.51)$ & 0.479 & $\mathrm{P}=0.000$ & $\mathrm{P}=0.728^{*}$ \\
\hline
\end{tabular}

* Student's t-test to compare mean differences between two measurements

** ICCs values $>0.75$ indicated good reliability

ICC - intraclass correlation coefficient, 95\% CI - 95\% confidence interval

\subsection{Construct validity}

An inverse association was found between the professional activities and the SSCRS_P score. More experienced nurses had significantly lower SSCRS_P scores than the less experienced ones (M: 94.38 vs $102.42, \mathrm{t}=-3.961, p<0.001, d_{\text {cohen }}=0.40,95 \%$ CI $[0.20$; $0.60])$.

\subsection{Criterion-related validity}

A bivariate intercorrelation matrix between the scores for all items in the SSCRS_P showed positive correlations at a 0.05 level or lower (most Pearson's correlation coefficients between 0.10 and 0.75 ) for all pairs of items except for item 13 . No statistically significant correlations were found for three pairs including this item. Also, all three factors were correlated with one another. However, the "Religiosity" factor stood out as it was inversely correlated with the other two (see Table S2: Appendix 2).

Discriminant validity was evaluated by comparing the scores for students who participated in a spiritual care training or a communication skills course and those who did not. The students who declared participating in SC training or a communication skills course has higher SSCRS_P scores than other respondents (Table 6).

Table 6. Results of the between-group comparisons of the SSCRS_P scores.

\begin{tabular}{lccccc}
\hline \multicolumn{1}{c}{$\mathbf{M}$} & SD & $\mathbf{t}$ & $p$-value $^{*}$ & $d(\mathbf{9 5} \% \mathbf{C I})$ \\
\hline \multicolumn{2}{l}{ Communication skills course } & & & & \\
\hline Yes & 100.43 & 17.00 & \multirow{2}{*}{3.181} & 0.002 & $\begin{array}{c}0.30 \\
(0.11 ; 0.48)\end{array}$ \\
No & 94.55 & 20.48 & & & \\
\hline Spiritual care training & & & & & 0.18 \\
\hline Yes & 96.54 & 20.31 & 2.265 & 0.024 & $(0.02 ; 0.33)$ \\
No & 93.03 & 19.45 & & &
\end{tabular}

* Student's t-test

$d$ - Cohen's d coefficient, 95\% CI - 95\% confidence interval

\section{Discussion}


This study demonstrated a substantial degree of similarity in the selected psychometric characteristics of the SSCRS_P and the original scale [25]. However, some significant differences were also observed. Factor analysis demonstrated that the SSCRS_P had a three-domain structure, whereas the original instrument consists of four domains [25]. This difference might correspond to its lower theoretical accuracy. The true theoretical accuracy of a scale could not be verified using a criterial analysis because of the lack of gold standard such as alternative Polish-language spirituality and SC instrument.

Instead, the structure of the SSCRS_P was verified based on the goodness of fit analysis for two models, using the CFA method. The analysis confirmed that the scale reduced to three domains was a better solution than the flour-domain scale. The inconsistencies in the results of both validation studies can be partially associated with the translation process and cultural differences. As the original SSCRS was developed in the UK, its adaptation for another cultural group required modification of some statements. Considering this, as well as cultural and linguistic differences, the factorial model created in this validation study could be considered correct. What is more, McSherry, Draper and Kendrick [25] suggested that additional research with similar populations and samples large enough to permit the CFA is recommended in order to validate and to refine this newly developed instrument.

The first domain identified in the SSCRS_P was "AcSC". Based on the content of its items, this domain refers to some specific activities that are associated with patients' expectations and nurses' beliefs related directly to those expectations. This dimension covers such activities as enabling the patient to undertake religious practices during hospital stay (e.g. by arranging a visit by the hospital chaplain or the patient's religious leader, having respect for religious and cultural beliefs of a patient, etc.), providing the patient with comfort, dignity and safety, and strengthening interpersonal relations (e.g. allowing patient's time for conversation, etc.).

The second identified domain was "EsSC" domain and included providing emotional support to patients in difficult life situations, especially those who experience strong emotions searching for a purpose and meaning in life, hope and intrinsic harmony. This dimension puts a particular emphasis on maintaining the psychological patients' wellbeing through adequate response to their emotional needs.

The third identified domain was "Religiosity", a three-item domain also included in the original version of the SSCRS and supporting the statement that spirituality is not only a concept associated with religion.

It needs to be stressed that the two domains identified in this validation study, "AcSC" and "EsSC", did not correspond directly with the three dimensions included in the original version of the SSCRS [25], but were compilations of the latter. After the adaptation of the SSCRS_P, the active tasks centring around the patients' needs were separated from those aimed at providing them with emotional support. Using this approach, we emphasize the practical applicability of these two domains, defining two principal routes through which the nurses can provide SC to their patients. This does not mean that both ways of SC are mutually exclusive, on the contrary, it may overlap. This approach is consistent with the holistic concept [25]. Analysing their personal resources, nurses can decide flexibly which way of SC is expected by the patient. Such attitude seems justified given current problems with shortage of nurses, a huge number of patients served by a single nurse and resultant work overload $[40,41]$. It may be a barrier to provide the whole spectrum of SC. Under such circumstances, the nurse can give priority to the AcSC to solve the patient's problems promptly and effectively. AcSC, EsSC care and both of them should be used as results of patient's expectation. The use of AcSC or/and EsSC should be adequate to the emotional state and individual patients' expectations. In the case of emotional case, the support can be provided in various ways, e.g. through showing interest and discussion about the patient's problems.

Considering all the above, the two dimensions seem to complement each other, and thus, to cover the full spectrum of SC. Furthermore, they reflect two equally important routes of SC provision, adjustable to nurse's personal resources, specific situational 
contexts and the patient-nurse relationship. Our results are consistent with previously published data showing that SC may include a plethora of activities addressed to both patients [20,25] and their families [42]. SC may be offered through various activities consistent with patients' expectations (e.g. respecting their dignity and privacy) [25], and/or be oriented on providing emotional support (e.g. for patients who pursue a purpose and meaning in life [20,25]. These two dimensions seem to be complementary, which was also reflected by the results of the factor analyses.

Among other psychometric properties of the SSCRS_P scale, its internal consistency, expressed by Cronbach's alpha, is worth mentioning. The values of Cronbach's alpha were satisfactory, well above the recommended threshold of 0.70 for two out of three identified domains. Only for the "Religiosity" domain, the alpha value was below the threshold, probably because of the low number of items included in this domain. The Cronbach's alpha for the entire SSCRS_P was highly satisfactory, confirming good internal consistency of the adapted version.

The results of the test-retest reliability analysis suggest that the SSCRS_P has good absolute stability. Regardless of the domain, the results obtained during the retest did not differ significantly from those recorded at the baseline. At the individual item level, the test-retest difference for item 17 is worth emphasizing. The proportion of respondents who did not agree with this statement during the retest was significantly higher than at the baseline. Perhaps, this difference reflected a cognitive change in the perception of morality as a spirituality component. Such a change might result from an unplanned natural effect of an extrinsic factor that influenced the whole study group rather than its members. To verify this finding, one should analyse all events that took place during two weeks between the test and the retest and involved all participants of the study. One such factor might be the curriculum of nursing education that included primarily clinical subjects related to the care and therapeutic education (e.g. oncological care), and a course in health psychology.

Determination of the SSCRS_P's potential to distinguish between various groups of respondents was based on two assumptions. The first of them was the difference in the attitudes to SC and the perception of spirituality in persons who previously participated in a communication skills course (CSC) and those who did not. Communication skills (CS) was chosen since they are included in the education standards for nurses and might support the provision of SC. During the education of nurses, questions related to SC, e.g. holistic care and patients' right to receive support from a religious leader, are addressed mainly during the ethics classes. The assumption mentioned above was confirmed during the analysis of the discriminant validity of the SSCRS_P. Participation in CSC had a beneficial effect on nurses' attitudes towards SC and their perception of spirituality, which was reflected by the results obtained with the SSCRS_P. Participation in CSC was previously postulated to improve the effectiveness of spiritual communication [43], and nurses who completed this kind of training seem to have fewer problems with an effective conversation with patients about their spiritual needs, purpose in life and issues around death and dying. This implies that CS might be an essential component during the provision of SC. This warrants the development of a spiritual communication curriculum and dedicated SC communication training [43]. The critical role of CS was also highlighted among the objectives of the EPICC project [8]. However, it needs to be stressed that the history of participation in a CSC was based solely on the respondents' declaration, and hence, the training might have taken various forms and covered a plethora of different topics. Therefore, the results of the discriminant validity analysis should be interpreted carefully and require verification in an interventional study with pre- and post-testing.

The second assumption verified during the discriminant validity analysis was the ability of the SSCRS_P to distinguish between the respondents who received SC training during previous education and those who did not. The analysis demonstrated that this kind of training influenced the respondents' attitudes toward SC, as well as altered their perception of spirituality. Our observations in this matter are consistent with the results published McSherry, Draper and Kendrick [25], Ross, et al. [44], Ross, et al. [45], Ross, et 
al. [46] as well as with the findings of Lewinson, et al. [47], according to whom appropriate educational activities (e.g. training) promote spiritual awareness which in turn contributes to a better quality of SC. Furthermore, the appropriately designed education programs help nurses to identify their knowledge gaps in relevant areas $[47,48]$.

The SSCRS_P may find practical application in the determination of attitudes towards SC and perception of spirituality among nurses pursuing the MSc title. The instrument consists of three domains with similar psychometric characteristics. The attitudes towards SC might be examined in newly employed nurses, and the results could constitute the basis for individual programs of competence development through the strengthening of personal resources. Moreover, the SSCRS_P could be used by the participants of continuing education programs, either as an element of self-assessment or as an additional instrument to measure the impact of teaching delivered by lecturers. Finally, the SSCRS_P may find application in the modification of postgraduate training curricula for nurses, to strengthen their soft skills in the area of SC.

\subsection{Study Limitations}

One drawback of the SSCRS_P is the fact that it cannot directly measure nurses' skills in terms of SC. The score reflects solely subjective attitudes of respondents towards SC. However, nurses could use the self-reported SSCRS_P score as guidance to improve their skills in terms of SC. Another potential limitation stems from the fact that this validation study included solely postgraduate students in nursing. Thus, the results should be interpreted carefully and not necessarily can be generalized onto the entire population of professionally active nurses.

\section{Conclusion}

AcSC, EsSC and religiosity provide the entire picture of SC perceived subjectively by Polish MSc students in nursing. All these three dimensions can be measured with the SSCRS_P, and the results can serve for either an individual (e.g. to improve one's personal resources) or a group (e.g. to revise the study curricula at nursing schools). Further validation studies of the SSCRS_P should include other specific groups of nurses. Furthermore, the reference ranges should be identified to standardize the SSCRS_P scores.

Author Contributions: Conceptualization, M.P.; Data curation, L.I, B.D., E.B., D.D., E.G., D.K., M.K., H.K. and J.L.; Formal analysis, M.P.; Investigation, L.I., B.D., W.M. and M.J.; Methodology, M.P. and M.J.; Supervision, J.G. and M.J.; Validation, M.P.; Writing - original draft, M.P., L.I., B.D., W.M. and M.J.; Writing - review \& editing, M.P. and M.J.

Funding: The study was conducted with the financial support of a research grant from the Medical University of Warsaw (PW/Z/10/5//20(1)).

Institutional Review Board Statement: The protocol of the study was approved by the Bioethics Committee at the Medical University of Warsaw (AKBE/152/16).

Informed Consent Statement: Informed consent was obtained from all subjects involved in the study.

Data Availability Statement: The data that support the findings of this study are openly available at https://doi.org/10.5281/zenodo.3818331..

Conflicts of Interest: The authors declare no potential conflicts of interest with respect to the research, authorship, and/or publication of this article.

Acknowledgments: We would like to thank Kamila Kraszewska for her help in digitizing the survey data. We would like to thank all nurses who participated in the study.

Appendix 1. Polish and English version of the Spirituality and Spiritual Care Rating Scale.

Appendix 2. Results of additional analysis. 


\section{References}

1. American Association of Colleges of Nursing. The Essentials of Baccalaureate Education for Professional Nursing Practice. Available online: https://www.aacnnursing.org/portals/42/publications/baccessentials08.pdf (accessed on 10-01-2022).

2. International Council of Nurses. The ICN Code of Ethics for Nurses. Available online: https://www.icn.ch/sites/default/files/inline-files/2012 ICN Codeofethicsfornurses \%20eng.pdf (accessed on 10-01-2022).

3. National Consensus Project for Quality Palliative Care. Clinical Practice Guidelines for Quality Palliative Care, 4th ed.; National Coalition for Hospice and Palliative Care: Richmond, VA, 2018.

4. Nursing and Midwifery Council. Future nurse: Standards of proficiency for registered nurses. Available online: https://www.nmc.org.uk/globalassets/sitedocuments/education-standards/future-nurse-proficiencies.pdf (accessed on 10-01-2022).

5. Abbasi, M.; Farahani-Nia, M.; Mehrdad, N.; Givari, A.; Haghani, H. Nursing students' spiritual well-being, spirituality and spiritual care. Iran J Nurs Midwifery Res 2014, 19, 242-247.

6. Azarsa, T.; Davoodi, A.; Khorami Markani, A.; Gahramanian, A.; Vargaeei, A. Spiritual wellbeing, Attitude toward Spiritual Care and its Relationship with Spiritual Care Competence among Critical Care Nurses. J Caring Sci 2015, 4, 309-320, doi:10.15171/jcs.2015.031.

7. Gall, T.L.; Charbonneau, C.; Clarke, N.H.; Grant, K.; Joseph, A.; Shouldice, L. Understanding the nature and role of spirituality in relation to coping and health: A conceptual framework. Canadian psychology/psychologie Canadienne 2005, 46, 88.

8. $\quad$ McSherry, W.; Ross, L.; Attard, J.; Van Leeuwen, R.; Giske, T.; Kleiven, T.; Boughey, A.; Network, E. Preparing undergraduate nurses and midwives for spiritual care: Some developments in European education over the last decade. Journal for the Study of Spirituality 2020, 10, 55-71.

9. Herdman, H.T.; Kamitsuru, S. NANDA international nursing diagnoses: definitions $\mathcal{E}$ classification 2018-2020; Georg Thieme: New York, 2017.

10. Hughes, B.; DeGregory, C.; Elk, R.; Graham, D.; Hall, E.; Ressallat, J. Spiritual care and nursing: A nurse's contribution and practice; HealthCare Chaplaincy Network: New York, NY, 2017.

11. DeKoninck, B.; Hawkins, L.A.; Fyke, J.P.; Neal, T.; Currier, K. Spiritual care practices of advanced practice nurses: a multinational study. The Journal for Nurse Practitioners 2016, 12, 536-544.

12. Taylor, E.J.; Mamier, I.; Ricci-Allegra, P.; Foith, J. Self-reported frequency of nurse-provided spiritual care. Applied nursing research : ANR 2017, 35, 30-35, doi:10.1016/j.apnr.2017.02.019.

13. Ruder, S. Spirituality in nursing: nurses' perceptions about providing spiritual care. Home Healthc Nurse 2013, 31, 356-367, doi:10.1097/NHH.0b013e3182976135.

14. Timmins, F.; Murphy, M.; Neill, F.; Begley, T.; Sheaf, G. An exploration of the extent of inclusion of spirituality and spiritual care concepts in core nursing textbooks. Nurse Educ Today 2015, 35, 277-282, doi:10.1016/j.nedt.2014.05.008.

15. Wu, L.F.; Liao, Y.C.; Yeh, D.C. Nursing student perceptions of spirituality and spiritual care. J Nurs Res 2012, 20, 219-227, doi:10.1097/jnr.0b013e318263d956.

16. Wu, L.F.; Tseng, H.C.; Liao, Y.C. Nurse education and willingness to provide spiritual care. Nurse Educ Today 2016, 38, 36-41, doi:10.1016/j.nedt.2016.01.001.

17. Puchalski, C.M.; Vitillo, R.; Hull, S.K.; Reller, N. Improving the spiritual dimension of whole person care: reaching national and international consensus. J Palliat Med 2014, 17, 642-656, doi:10.1089/jpm.2014.9427. 
18. Jaberi, A.; Momennasab, M.; Yektatalab, S.; Ebadi, A.; Cheraghi, M.A. Spiritual Health: A Concept Analysis. J Relig Health 2019, 58, 1537-1560, doi:10.1007/s10943-017-0379-z.

19. Nardi, D.; Rooda, L. Spirituality-based nursing practice by nursing students: an exploratory study. J Prof Nurs 2011, 27, 255-263, doi:10.1016/j.profnurs.2011.03.006.

20. Harrad, R.; Cosentino, C.; Keasley, R.; Sulla, F. Spiritual care in nursing: an overview of the measures used to assess spiritual care provision and related factors amongst nurses. Acta Biomed 2019, 90, 44-55, doi:10.23750/abm.v90i4-S.8300.

21. Büssing, A.; Balzat, H.J.; Heusser, P. Spiritual needs of patients with chronic pain diseases and cancer validation of the spiritual needs questionnaire. Eur J Med Res 2010, 15, 266-273, doi:10.1186/2047-783x-15-6-266.

22. Daaleman, T.P.; Reed, D.; Cohen, L.W.; Zimmerman, S. Development and preliminary testing of the quality of spiritual care scale. J Pain Symptom Manage 2014, 47, 793-800, doi:10.1016/j.jpainsymman.2013.06.004.

23. Howden, J.W. Development and psychometric characteristics of the Spirituality Assessment Scale. Texas Woman's University, 1992.

24. Makkar, S.; Singh, A.K. Development of a spirituality measurement scale. Current Psychology 2021, 40, 14901497.

25. McSherry, W.; Draper, P.; Kendrick, D. The construct validity of a rating scale designed to assess spirituality and spiritual care. Int. J. Nurs. Stud. 2002, 39, 723-734, doi:10.1016/S0020-7489(02)00014-7.

26. Sharma, R.K.; Astrow, A.B.; Texeira, K.; Sulmasy, D.P. The Spiritual Needs Assessment for Patients (SNAP): development and validation of a comprehensive instrument to assess unmet spiritual needs. J Pain Symptom Manage 2012, 44, 44-51, doi:10.1016/j.jpainsymman.2011.07.008.

27. Chandramohan, S.; Bhagwan, R. Spirituality and nursing. In The Routledge International Handbook of Spirituality in Society and the Professions; Routledge: 2019; pp. 205-212.

28. Ross, L. Spiritual care in nursing: an overview of the research to date. J. Clin. Nurs. 2006, 15, 852-862.

29. Stranahan, S. Spiritual perception, attitudes about spiritual care, and spiritual care practices among nurse practitioners. Western journal of nursing research 2001, 23, 90-104, doi:10.1177/01939450122044970.

30. Department of Nurses and Midwives. Strategy for the development of nursing and midwifery in Poland; Polish Ministry of Health: Warsaw, 2017.

31. Bartlett , J.; Kotrlik, J.; Higgins, C. Organizational research: Determining appropriate sample size in survey research appropriate sample size in survey research. Information technology, learning, and performance journal 2001, 19, 43.

32. Boateng, G.O.; Neilands, T.B.; Frongillo, E.A.; Melgar-Quiñonez, H.R.; Young, S.L. Best Practices for Developing and Validating Scales for Health, Social, and Behavioral Research: A Primer. Frontiers in public health 2018, 6, 149-149, doi:10.3389/fpubh.2018.00149.

33. Terwee, C.B.; Bot, S.D.; de Boer, M.R.; van der Windt, D.A.; Knol, D.L.; Dekker, J.; Bouter, L.M.; de Vet, H.C. Quality criteria were proposed for measurement properties of health status questionnaires. Journal of clinical epidemiology 2007, 60, 34-42.

34. Kaiser, H.F. The varimax criterion for analytic rotation in factor analysis. Psychometrika 1958, 23, doi:10.1007/BF02289233.

35. Fabrigar, L.R.; Wegener, D.T.; MacCallum, R.C.; Strahan, E.J. Evaluating the use of exploratory factor analysis in psychological research. Psychological methods 1999, 4, 272.

36. Hooper, D.; Coughlan, J.; Mullen, M. Structural equation modelling: Guidelines for determining model fit. Articles 2008, 2. 
37. Tavakol, M.; Dennick, R. Making sense of Cronbach's alpha. International Journal of Medical Education 2011, 2, 5355, doi:10.5116/ijme.4dfb.8dfd.

38. Sullivan, G.M. A primer on the validity of assessment instruments. Journal of Graduate Medical Education 2011, 3, 119-120, doi:10.4300/JGME-D-11-00075.1.

39. Muthén, L.; Muthén, B. The comprehensive modelling program for applied researchers: user's guide. 2012. Mplus.[Google Scholar].

40. Ausserhofer, D.; Zander, B.; Busse, R.; Schubert, M.; De Geest, S.; Rafferty, A.M.; Ball, J.; Scott, A.; Kinnunen, J.; Heinen, M.; et al. Prevalence, patterns and predictors of nursing care left undone in European hospitals: results from the multicountry cross-sectional RN4CAST study. BMJ Qual Saf 2014, 23, 126-135, doi:10.1136/bmjqs-2013002318 .

41. Marć, M.; Bartosiewicz, A.; Burzyńska, J.; Chmiel, Z.; Januszewicz, P. A nursing shortage - a prospect of global and local policies. International nursing review 2019, 66, 9-16, doi:10.1111/inr.12473.

42. Lovering, S. Arab Muslim nurses experiences of the meaning of caring. 2008.

43. Wittenberg, E.; Ragan, S.L.; Ferrell, B. Exploring Nurse Communication About Spirituality. Am J Hosp Palliat Care 2017, 34, 566-571, doi:10.1177/1049909116641630.

44. Ross, L.; van Leeuwen, R.; Baldacchino, D.; Giske, T.; McSherry, W.; Narayanasamy, A.; Downes, C.; Jarvis, P.; Schep-Akkerman, A. Student nurses perceptions of spirituality and competence in delivering spiritual care: a European pilot study. Nurse Educ Today 2014, 34, 697-702, doi:10.1016/j.nedt.2013.09.014.

45. Ross, L.; Giske, T.; van Leeuwen, R.; Baldacchino, D.; McSherry, W.; Narayanasamy, A.; Jarvis, P.; SchepAkkerman, A. Factors contributing to student nurses'/midwives' perceived competency in spiritual care. Nurse Educ Today 2016, 36, 445-451, doi:10.1016/j.nedt.2015.10.005.

46. Ross, L.; McSherry, W.; Giske, T.; van Leeuwen, R.; Schep-Akkerman, A.; Koslander, T.; Hall, J.; Steenfeldt, V.; Jarvis, P. Nursing and midwifery students' perceptions of spirituality, spiritual care, and spiritual care competency: A prospective, longitudinal, correlational European study. Nurse Educ Today 2018, 67, 64-71, doi:10.1016/j.nedt.2018.05.002.

47. Lewinson, L.P.; McSherry, W.; Kevern, P. Spirituality in pre-registration nurse education and practice: A review of the literature. Nurse Educ Today 2015, 35, 806-814, doi:10.1016/j.nedt.2015.01.011.

48. Lewinson, L.P.; McSherry, W.; Kevern, P. “Enablement” - Spirituality Engagement in Pre-Registration Nurse Education and Practice: A Grounded Theory Investigation. Religions 2018, 9, 356. 